\title{
PROGNOSTIC BIOMARKERS IN TRIPLE NEGATIVE BREAST CANCER AS A POTENTIAL TARGET FOR FUTURE DRUG DISCOVERY
}

\author{
MEKHLA GUPTA ${ }^{1}$, SEEMA KHANNA ${ }^{1}$, RAJESH KUMAR SINGH ${ }^{2}$, SANJEEV KUMAR GUPTA ${ }^{1 *}$ \\ ${ }^{1}$ Department of General Surgery, Institute of Medical Sciences, Banaras Hindu University, Varanasi, Uttar Pradesh, India. ${ }^{2}$ Department of \\ Dravyaguna, Institute of Medical Sciences, Banaras Hindu University, Varanasi, Uttar Pradesh, India. \\ Email: seemakhanna119@rediffmail.com \\ Received: 14 February 2016, Revised and Accepted: 23 March 2017
}

ABSTRACT

Breast cancer is the most common malignancy in women globally, in which triple-negative breast cancer (TNBC) is more aggressive with poor prognosis and very less response to targeted hormone based treatment. It is a major cause of deaths among the women with breast cancer because of very few treatment options. The biomarkers could be a product of cancerous cell or molecule generated in response to cancer. It is used to understand the mechanism, prognosis, diagnosis as well as target for design and discovery of new drugs. The purpose of the study is to give a brief review on markers of TNBC.

Keywords: Breast cancer, Triple-negative breast cancer, Biomarkers, Drug discovery, Diagnosis.

(C) 2017 The Authors. Published by Innovare Academic Sciences Pvt Ltd. This is an open access article under the CC BY license (http://creativecommons. org/licenses/by/4. 0/) DOI: http://dx.doi.org/10.22159/ajpcr.2017.v10i6.17727

\section{INTRODUCTION}

Breast cancer is one of the most common malignant tumors among women, and it is a heterogeneous type of disease because of their therapy response. We can define its molecular subtypes by immunohistochemistry (IHC). Triple-negative breast cancer (TNBC) is one of the molecular subtypes of breast carcinoma represents by the lack of expression of estrogen receptor (ER), progesterone receptor (PR), and human epidermal growth factor receptor (HER 2). TNBC accounts for about $12.5-15 \%$ of all breast cancers [1]. TN breast carcinoma is more frequent in younger age $(<50$ years) with more aggressiveness and poorer prognosis. These are more prevalent in the AfricanAmerican population [2]. They need typical and differential molecular profile and distinct patterns of metastasis [3]. They metastasize commonly with lungs, central nervous system, and liver. TNBC varies $16-42 \%$ in BRCA mutation $[4,5]$. TNBC can be further defined by two groups, i.e.,, basal-like (BL) and non-BL. Although all BL tumors are not triple negative [6]. However, in TN disease, all intrinsic molecular subtypes can be identified and majority tends to BL subtype (86\%, depending from the various other studies done by Researchers) [7]. Initially, on the basis of hierarchical clustering, identified four intrinsic subtypes of breast cancers (BL, HER 2 enriched, luminal, and normal breast-like), which exhibits gene expression patterns. Subsequently, luminal breast cancer leads to sub- stratified into luminal $\mathrm{A}$ and luminal B, which expressed significantly in the classification system for prognosis [8-10]. For TNBC, there is no standard chemotherapy till date. BL-TNBC accounts up to approximately $25-80 \%$ of all TNBC patients [11]. The above data have been taken by IHC profiling for epidermal growth factor receptor (EGFR), CK 5/6 +, ER-, HER 2 -. BLTNBC can be further separated into two subgroups, BL1 and BL2 [12]. $\mathrm{BL}-\mathrm{TNBC}$ exhibits the highest pathologic complete response ( $\mathrm{pCR}$ ) rates following chemotherapy [13]. However, various trials are going on and have been conducted in unselected patient's populations. This review explores the biological features and biomarker expression profile of TNBC. In this article, we focused to understand and classified the TNBC based on similar gene expression, biological functions, and their clinical outcomes. The purpose of this study is to revise the specific therapeutic strategies, on the basis of gene profile having different for each specific TNBC subtypes. Hence, anti-EGFR, anti-vascular endothelial growth factor (VEGF), anti-p53, and anti-ki67, the prognostic biomarkers may provide a potential treatment option for TNBC.

\section{Selection criteria and search}

We conducted a PubMed, Medline search till July 2016, using the term "TNBC," “Gene expression profiling," “EGFR," "VEGF," “ki67," "p53," and "breast cancer" followed by "AND/OR" without any date restriction (Table 1). Publications written in other than the English language were excluded. We cross-referred the information obtained to identify clinically effective TNBC groupings with similar gene expression, biological functions, and clinical outcomes.

\section{EGFR}

Human EGFR (also known as HER 1/Erb 1) and its relative three other genes human EGFR 2, 3, and 4 (HER 2/Erb 2, also known as the neu oncogene, HER 3/Erb 3, and HER4/Erb 4) plays a major role in the control of cell growth and proliferation $[14,15]$. The defect in these receptors like genetic abnormalities leads to major defects in cancer cells [16]. Truly EGFR is the first epidermal receptor which recognizes as an oncogene $[17,18]$. EGFR is a 1,70,000 membranes bound tyrosine kinase. The protein product of EGFR plays a very major role in cell proliferation, protection against apoptosis and migration in activation of intracellular mediated pathways [19]. EGFR family inhibitors lead to two major classes: Monoclonal antibody that targets the extracellular module of this receptor: And other is small molecules that target the intracellular tyrosine kinase domain. Some FDA approved antibodies, cetuximab, and panitumumab target EGFR, while pertuzumab and trastuzumab target HER 2 [20]

EGFR highly overexpressed in majority of BL TN tumors [21]. BL $\mathrm{TN}$ tumors have seeking attention due to recognition as a distinct entity and due to poor prognosis that the diagnosis indicates. Some of the studies demonstrated TN tumors have a good response to an adjuvant anthracycline- based chemotherapy [22]. However, various clinical trials are still going on to target the possible therapeutics for TN tumors. Targeted anti-EGFR antibodies (e.g., cetuximab) and EGFR tyrosine kinase inhibitors (e.g., gefitinib) can provide a possible therapy modality $[23,24]$. As the outcome, the combination of cetuximab and gefitinib, give more promising result while did not showed the appropriate response by independent agent as compared to a study done [25]. In a cohort of unselected patients, EGFR-TKIs given as monotherapy did not provide any clinical benefit. A study showed the contradictory result, as indicates the inactivation of EGFR pathway 
Table 1: PubMed literature search

Termsearched classifiedbased onimmunohistochemistry Inclusion

Limitations (exclusion)

Language

Time period
Breast cancer OR

Triple negative breast cancer OR basal-like breast cancer AND

IHC OR IHC AND

Biomolecular markers OR molecular subtype OR ER -ve AND PR -ve AND

HER 2 neu -ve

Humans only

Abstract and full text

Editorial

News

Case reports

Animals

Plants

English only

Till July 2016

IHC: Immunohistochemistry

Table 2: EGFR expression in TNBC (modified from Yadav et al. 2015

\begin{tabular}{llll}
\hline $\begin{array}{l}\text { Total } \\
\text { number }\end{array}$ & TNBC (n) & $\begin{array}{l}\text { EGFR } \\
\text { expression (\%) }\end{array}$ & Reference \\
\hline- & 653 & 30 & Teng et al. 2011 \\
200 & 198 & 91 & Yue et al. 2015 \\
7048 & 767 & 30 & Thike et al. 2010 \\
683 & 136 & 7.4 & Patil et al. 2011 \\
- & 21 BLBC & 57 & Nielsen et al. 2007 \\
1726 & 282 & 37 & Rakha et al. 2007 \\
1132 & 103 & 23.3 & Mehdizadeh et al. 2102 \\
564 & 48 & 41 & Ryden et al. 2010 \\
\hline
\end{tabular}

TNBC: Triple-negative breast cancer

Table 3: VEGF expression in TNBC

\begin{tabular}{llll}
\hline $\begin{array}{l}\text { Total } \\
\text { number }\end{array}$ & TNBC & $\begin{array}{l}\text { VEGFR-2 in } \\
\text { TNBC (\%) }\end{array}$ & Reference \\
\hline 96 & 43 & 90.5 & Abeer Bahhnassy et al. 2015 \\
1132 & 103 & 93.2 & Mehdizadeh et al. 2012 \\
- & 73 & 77 & Iosifidou et al. 2009 \\
70 & 27 & 54 & Chanana et al. 2012 \\
69 & 35 & 34 & Andre et al. 2009 \\
679 & 87 & $\begin{array}{l}\text { Higher } \\
\text { VEGF level }\end{array}$ & \\
& & Linderholm et al. 2008 & \\
\hline
\end{tabular}

TNBC: Triple-negative breast cancer, VEGF: Vascular endothelial growth factor, VEGFR: Vascular endothelial growth factor receptor

in TNBC by giving EGFR inhibitors [26]. Some authors demonstrated that one-third of BL TNBC develops distance metastasis in which EGFR markers were helpful in diagnosis of high risk of metastatic disease [27]. A study reported that IHC EGFR positive patients were significantly more likely to develop distance metastasis, which depicts EGFR as an important prognostic marker for distance metastasis. Whereas, in EGFR expression, there is no significant difference between TN tumors with metastasis and those without metastasis. A study showed a high frequency of EGFR expression, i.e., 91.3\% in BL subtype of TN breast cancer, which suggests that this marker may be helpful to detect metastatic BL TN breast tumors and may be beneficial to the patients for treatment with anti-EGFR drugs [27]. Expressions of EGFR in TNBC from various studies has been shown in Table 2.

Ki67

Ki67 is nuclear non-histone protein and was named after its Researcher's location, as, Ki stands for the University of Kiel, Germany, and 67 refers to the number of the clone on the 96-well plate. Ki67 gene is known for its proliferating characteristics, as it is marker of proliferation. The expression of ki67 at peak in the phase of G1, S and
G2 phase of cell cycle and absent in G0 phase [28]. Ki67 may predict as pathological exemption rate in breast cancer patient who followed neoadjuvant chemotherapy, whereas increased level of ki67 following neoadjuvant chemotherapy indicates a poor prognosis [29]. Hence, ki67 has been considered to be one of the most relevant marker indicators in detecting the proliferation of the tumor cells [30]. According to a study, ki67 significantly expressed more in TNBC group when compared nonTNBC patients [31]. The expression of ki67 in TNBC is higher than that of high-grade non-TNBC, which indicates that ki67 may play a role in prognosis of TNBC [32]. A study conducted in 2011, explained that TNBC with the higher expression of ki67 was associated with more aggressive clinicopathological features despite a higher pCR rate [33]. Some research articles suggest that the expression level of ki67 is presently considered to have significant prognostic and predictive values $[34,35]$.

Ki67 expressed significantly in a higher stage of TN tumors and high lymph node metastasis [36]. They also suggested that the patients having higher expression of ki67 showed a significantly worse overall survival (OS) time. Hence, E-cadherin and ki67 when combined might be useful prognostic markers for adjuvant chemotherapy in Stage II TNBC patients. The debate on prognosis of ki67 in TNBC is still open, although various studies have established a relation between ki67 and overall and disease-free survival. In a study, it is also suggested that the assessment of the main prognostic and predictive parameters such as ER, PgR, and HER 2 including along with ki67 should offer to the patients and their physicians a strong background on which the final therapeutic decision can be safely taken [37]. Ki67 leads to most promising yet controversial biomarker in breast cancer, which is implementing routinely in some of the pathology department but not all. Ki67 can be controversial but clinically implemented biomarker along with well-established biomarkers of ER, PR, and HER 2 are currently marketed gene expression signature [38]. In several metaanalyses, it has been shown that ki67 as a prognostic marker as well as predictive marker (in neoadjuvant therapeutics). The "optimal" cut point of expression of ki67 has been still is under a big discussion topic which leads to matter that ki67 is a continuous marker, expressing the severe variation of the proliferative rates in different cancers. Due to this variation from several research and clinical trials, it is depicted that level of ki67 is quite difficult to standardize. However although, ki67 may be clinically interpreted directly by dividing its expression into two groups, i.e., tumors with a very low or very high expression of this marker. Instead of this limitation, the assessment of proliferation for cancer cell characterization ki67 plays an important pathological role [39].

\section{VEGF}

To support tumor growth, there is a requirement of increase formation of blood vessels. Tumor angiogenesis is a multistep process requiring signaling between tumor cells and several other cell types within the internal environment of tumor cells. Due to this process, they activate 
Table 4: Expression of p53 in TNBC

\begin{tabular}{llll}
\hline $\begin{array}{l}\text { Total } \\
\text { number }\end{array}$ & TNBC & p53 in TNBC & Reference \\
\hline- & 134 & $\begin{array}{l}\text { Higher than } \\
\text { non-TNBC (\%) }\end{array}$ & Nakagawa et al. 2011 \\
683 & 135 & 47.8 & Patil et al. 2011 \\
11 & 11 & 82 & Nielsen et al. 2004 \\
135 & 32 & 40.6 & Chae et al. 2008 \\
1726 & 282 & 56 & Rakha et al. 2007 \\
- & - & 82 & Foulker et al. 2004 \\
\hline
\end{tabular}

TNBC: Triple-negative breast cancer

overexpression of pro-angiogenic factors by the tumor cells, such as VEGF, referred to as the "angiogenic switch" [40]. VEGFs when binds to one receptor, it stimulates dimerization of receptor and initiates signal pathway which promotes growth and migration [41]. The tumor vascular growth can be inhibited by antiangiogenic therapy by interfering with the intracellular signaling of VEGF and VEGF receptor (VEGFR) [42-44]. A monoclonal humanized antibody was designed named as Bevacizumab and Ramucirumab to inhibit the interaction between VEGF ligands and receptors $[45,46]$. Expression of VEGF is controlled by many stimuli such as hypoxia, nitric oxide, HER 2, Tumor suppressor genes, growth factor, and oncogenes [47]. VEGF regulates neovascularization in tumors, by increasing the level of antiapoptotic proteins such as $\mathrm{Bcl} 2$, survivin, and XIAP. The endothelial cells undergo apoptosis, and newly formed vessels disintegrate due to its absence $[48,49]$

Now when it comes to TNBC, some researchers suggest that VEGF is one of the promising prognostic molecular markers. The expression of VEGF is elevated in DCIS and invasive breast cancer, and it is utilized for prognosis in breast carcinoma. The quantification of VEGF by IHC or immunoassay has shown a significant correlation with density. Higher expression of vascular density in breast tumors has been correlated with more aggressive tumor behavior and poor survival. Hence, microvessel density is now considered as one of the important factors which effects survival [50]. In a study conducted in 2009, was concluded that higher VEGF expressions are associated with shorter disease-free survival (DFS), OS, and DFS in TNBC [51]. It also stated that there was a direct correlation between serum and tissue level of VEGF to Grade III tumors, larger tumor size, positive lymph node, and poor survival with a decrease in level with chemotherapy. Expressions of VEGF in TNBC from various studies has been shown in Table 3

\section{P53}

P53 is a tumor suppressor gene which is encoded by the TP53 gene. P53 plays an important role as it regulates cell growth, proliferation, multiplication and apoptosis, and promotes stability of chromosomes. Any disruption of this function due to a mutation in p53 gene is done due to cellular stress by many pathways which are dependent on upstream regulatory kinase. $18-25 \%$ of primary breast carcinoma showed p53 mutation [52]. According to a study, expression of p53 is significantly higher in TNBC comparatively than non-TNBC, which indicates in worse prognosis of TNBC [32]. Due to higher expression of p53 in TN tumors, it may be used as predictors for response to chemotherapeutic agents. The majority of breast tumors with the p53 mutation was ER negative and associated with decreased DFS [53]. Although the exact mechanism, which may involve in this association is still unclear.

In several studies, it is denoted that p53 is more favorable to response to NAC in patients with TNBC. For instance, p53 overexpression was strongly correlated with pCR rate in TNBCs [54]. The level of p53 expression in TNBC with nodal metastasis was significantly higher than non-TNBC with same metastasis [55]. Heterogeneous p53 mutations, few of proteins may not be able to produce stability, which is detectible by IHC. The positive IHC results of p53 may be due to binding with other cellular proteins which gives accumulation of p53 expression.
Studies conducted by various researchers suggest that activation of p53 gene is associated with aggressiveness of breast tumor and in TNBC patients; it significantly decreases the rate of DFS and OS [21,56-58]. It can be used for segregation of subclass, i.e., BL from core TNBC along with EGFR and cytokeratin [59]. In TNBC patients, p53 mutations are associated with poor response to chemotherapy [60]. Study conducted 2016, demonstrated that elevated p53 expression in TNBC patients, presented the worst prognosis [61]. Measurement of p53 expression may assist in making treatment decisions and in predicting response to treatment, when apply before starting neoadjuvant chemotherapy, as when p53 combines with ki67, gives great predictive accuracy[62]. The frequency of p53 mutations was found to be higher in basal breast cancer as compared to Luminal type tumors [63]. Expressions of p53 in TNBC from various studies has been shown in Table 4.

\section{CONCLUSION}

TNBC is a cause of significant breast cancer mortality because of very few treatment options. Biomarkers can be useful as prognostic or predictive indicators which also suggest possible targeted therapies. TNBC are associated with a significantly higher expression of VEGF, EGFR, ki67, and p53 as compared with non-TNBC, which indicates the poorer prognosis in TN tumors. The emphasis should be put on research for targeted therapies of TNBC. New therapeutics alternatives should be investigated for patients with this subtype of breast cancer.

\section{REFERENCES}

1. Rastelli F, Biancanelli S, Falzetta A, Martignetti A, Casi C, Bascioni R, et al. Triple-negative breast cancer: Current state of the art. Tumori 2010;96(6):875-88.

2. Carey LA, Perou CM, Livasy CA, Dressler LG, Cowan D, Conway K, et al. Race, breast cancer subtypes, and survival in the Carolina Breast Cancer Study. JAMA 2006;295(21):2492-502.

3. Rakha EA, Ellis IO. Triple-negative/basal-like breast cancer: Review. Pathology 2009;41(1):40-7.

4. Atchley DP, Albarracin CT, Lopez A, Valero V, Amos CI, Gonzalez-Angulo AM, et al. Clinical and pathologic characteristics of patients with BRCA-positive and BRCA-negative breast cancer. J Clin Oncol 2008;26(26):4282-8.

5. Gonzalez-Angulo AM, Timms KM, Liu S, Chen H, Litton JK, Potter J, et al. Incidence and outcome of BRCA mutations in unselected patients with triple receptor-negative breast cancer. Clin Cancer Res 2011;17(5):1082-9.

6. Anders C, Carey LA. Understanding and treating triple-negative breast cancer. Oncology (Williston Park) 2008;22(11):1233-9.

7. Prat A, Pineda E, Adamo B, Galván P, Fernández A, Gaba L, et al. Clinical implications of the intrinsic molecular subtypes of breast cancer. Breast 2015;24 Suppl 2:S26-35.

8. Hu Z, Fan C, Oh DS, Marron JS, He X, Qaqish BF, et al. The molecular portraits of breast tumors are conserved across microarray platforms. BMC Genomics 2006;7:96.

9. Sørlie T, Perou CM, Tibshirani R, Aasf T, Geislerg S, Johnsen H, et al. Gene expression patterns of breast carcinomas distinguishes tumor subclasses with clinical implications. Proc Natl Acad Sci U S A 2001;98(19):10869-74

10. Sorlie T, Tibshirani R, Parker J, Hastie T, Marron JS, Nobel A, et al. Repeated observation of breast tumor subtypes in independent gene expression data sets. Proc Natl Acad Sci U S A 2003;100(14):8418-23.

11. Le Du F, Eckhardt BL, Lim B, Litton JK, Moulder S, Meric-Bernstam F, et al. Is the future of personalized therapy in triple-negative breast cancer based on molecular subtype? Oncotarget 2015;6(15):12890-908.

12. Lehmann BD, Bauer JA, Chen X, Sanders ME, Chakravarthy AB, Shyr Y, et al. Identification of human triple-negative breast cancer subtypes and preclinical models for selection of targeted therapies. J Clin Invest 2011;121(7):2750-67.

13. Rouzier R, Perou CM, Symmans WF, Ibrahim N, Cristofanilli M, Anderson K, et al. Breast cancer molecular subtypes respond differently to preoperative chemotherapy. Clin Cancer Res 2005;11(16):5678-85.

14. Avraham R, Yarden Y. Feedback regulation of EGFR signalling: Decision making by early and delayed loops. Nat Rev Mol Cell Biol 2011;12(2):104-17.

15. Lemmon MA, Schlessinger J, Ferguson KM. The EGFR family: Not so prototypical receptor tyrosine kinases. Cold Spring Harb Perspect Biol 
2014;6(4):a020768.

16. Arteaga CL, Engelman JA. ERBB receptors: From oncogene discovery to basic science to mechanism-based cancer therapeutics. Cancer Cell 2014;25(3):282-303.

17. Downward J, Parker P, Waterfield MD. Autophosphorylation sites on the epidermal growth factor receptor. Nature 1984;311(5985):483-5.

18. Ullrich A, Coussens L, Hayflick JS, Dull TJ, Gray A, Tam AW, et al. Human epidermal growth factor receptor cDNA sequence and aberrant expression of the amplified gene in A431 epidermoid carcinoma cells. Nature 1984;309(5967):418-25.

19. Quintela I, Corte MD, Allende MT, Vazquez J, Rodríguez JC, Bongera M, et al. Expression and prognostic value of EGFR in invasive breast cancer. Oncol Rep 2005;14(6):1655-63.

20. Kovacs E, Zorn JA, Huang Y, Barros T, Kuriyan J. A structural perspective on the regulation of the epidermal growth factor receptor. Annu Rev Biochem 2015;84:739-64.

21. Peng Y. Potential prognostic tumor biomarkers in triple-negative breast carcinoma. Beijing Da Xue Xue Bao 2012;44(5):666-72.

22. Nofech-Mozes S, Trudeau M, Kahn HK, Dent R, Rawlinson E, Sun P, et al. Patterns of recurrence in the basal and non-basal subtypes of triplenegative breast cancers. Breast Cancer Res Treat 2009;118(1):131-7.

23. Viale G, Rotmensz N, Maisonneuve P, Bottiglieri L, Montagna E, Luini A, et al. Invasive ductal carcinoma of the breast with the "triple-negative" phenotype: Prognostic implications of EGFR immunoreactivity. Breast Cancer Res Treat 2009;116(2):317-28.

24. Oliveras-Ferraros C, Vazquez-Martin A, López-Bonet E, Martín-Castillo B, Del Barco S, Brunet J, et al. Growth and molecular interactions of the anti-EGFR antibody cetuximab and the DNA crosslinking agent cisplatin in gefitinib-resistant MDA-MB-468 cells: New prospects in the treatment of triple-negative/basal-like breast cancer. Int J Oncol 2008;33(6):1165-76.

25. Masuda H, Zhang D, Bartholomeusz C, Doihara H, Hortobagyi GN, Ueno NT. Role of epidermal growth factor receptor in breast cancer. Breast Cancer Res Treat 2012;136(2):331-45.

26. Carey LA. Neoadjuvant trials of human epidermal growth factor receptor 2 targeting: How many drugs do we need? J Clin Oncol 2012;30(16):1909-11.

27. Sutton LM, Han JS, Molberg KH, Sarode VR, Cao D, Rakheja D, et al. Intratumoral expression level of epidermal growth factor receptor and cytokeratin $5 / 6$ is significantly associated with nodal and distant metastases in patients with basal-like triple-negative breast carcinoma. Am J Clin Pathol 2010;134(5):782-7.

28. Lopez F, Belloc F, Lacombe F, Dumain P, Reiffers J, Bernard P, et al. Modalities of synthesis of Ki67 antigen during the stimulation of lymphocytes. Cytometry 1991;12(1):42-9.

29. Masuda H, Masuda N, Kodama Y, Ogawa M, Karita M, Yamamura J, et al. Predictive factors for the effectiveness of neoadjuvant chemotherapy and prognosis in triple-negative breast cancer patients. Cancer Chemother Pharmacol 2011;67(4):911-7.

30. Zheng JN, Sun YF, Pei DS, Liu JJ, Ma TX, Han RF, et al. Treatment with vector-expressed small hairpin RNAs against Ki67 RNA-induced cell growth inhibition and apoptosis in human renal carcinoma cells. Acta Biochim Biophys Sin (Shanghai) 2006;38(4):254-61.

31. Li H, Han X, Liu Y, Liu G, Dong G. Ki67 as a predictor of poor prognosis in patients with triple-negative breast cancer. Oncol Lett 2015;9(1):149-52

32. Han JS, Cao D, Molberg KH, Sarode VR, Rao R, Sutton LM, et al. Hormone receptor status rather than HER2 status is significantly associated with increased $\mathrm{Ki}-67$ and p53 expression in triple-negative breast carcinomas, and high expression of $\mathrm{Ki}-67$ but not p53 is significantly associated with axillary nodal metastasis in triple-negative and high-grade non-triple-negative breast carcinomas. Am J Clin Pathol 2011;135(2):230-7.

33. Keam B, Im SA, Lee KH, Han SW, Oh DY, Kim JH, et al. Ki-67 can be used for further classification of triple negative breast cancer into two subtypes with different response and prognosis. Breast Cancer Res 2011;13(2):R22.

34. Jones RL, Salter J, A'Hern R, Nerurkar A, Parton M, Reis-Filho JS, et al. The prognostic significance of $\mathrm{Ki} 67$ before and after neoadjuvant chemotherapy in breast cancer. Breast Cancer Res Treat 2009; 116(1):53-68.

35. Dowsett M, Smith IE, Ebbs SR, Dixon JM, Skene A, A'Hern R, et al. Prognostic value of Ki67 expression after short-term presurgical endocrine therapy for primary breast cancer. J Natl Cancer Inst 2007;99(2):167-70.

36. Kashiwagi S, Yashiro M, Takashima T, Aomatsu N, Ikeda K, Ogawa Y, et al. Advantages of adjuvant chemotherapy for patients with triplenegative breast cancer at Stage II: Usefulness of prognostic markers E-cadherin and Ki67. Breast Cancer Res 2011;13(6):R122.

37. Viale G. Pathological work up of the primary tumor: Getting the proper information out of it. Breast 2011;20 Suppl 3:S82-6.

38. Kos Z, Dabbs DJ. Biomarker assessment and molecular testing for prognostication in breast cancer. Histopathology 2016;68(1):70-85.

39. Denkert C, Budczies J, von Minckwitz G, Wienert S, Loibl S, Klauschen F. Strategies for developing Ki67 as a useful biomarker in breast cancer. Breast 2015;24 Suppl 2:S67-72.

40. Fan F, Schimming A, Jaeger D, Podar K. Targeting the tumor microenvironment: Focus on angiogenesis. J Oncol 2012;2012:281261.

41. Grimm D, Bauer J, Ulbrich C, Westphal K, Wehland M, Infanger M, et al. Different responsiveness of endothelial cells to vascular endothelial growth factor and basic fibroblast growth factor added to culture media under gravity and simulated microgravity. Tissue Eng Part A 2010;16(5):1559-73.

42. Claesson-Welsh L, Welsh M. VEGFA and tumour angiogenesis. J Intern Med 2013;273(2):114-27.

43. Wehland $M$, Bauer $J$, Magnusson NE, Infanger $M$, Grimm $D$. Biomarkers for anti-angiogenic therapy in cancer. Int $\mathrm{J}$ Mol Sci 2013;14(5):9338-64.

44. Leite de Oliveira R, Hamm A, Mazzone M. Growing tumor vessels: More than one way to skin a cat - Implications for angiogenesis targeted cancer therapies. Mol Aspects Med 2011;32(2):71-87.

45. Miller KD, Chap LI, Holmes FA, Cobleigh MA, Marcom PK, Fehrenbacher L, et al. Randomized phase III trial of capecitabine compared with bevacizumab plus capecitabine in patients with previously treated metastatic breast cancer. J Clin Oncol 2005;23(4):792-9.

46. Mackey J, Gelmon K, Martin M, McCarthy N, Pinter T, Rupin M, et al. TRIO-012: A multicenter, multinational, randomized, doubleblind phase III study of IMC-1121B plus docetaxel versus placebo plus docetaxel in previously untreated patients with HER2-negative, unresectable, locally recurrent or metastatic breast cancer. Clin Breast Cancer 2009;9(4):258-61.

47. Benjamin LE, Keshet E. Conditional switching of vascular endothelial growth factor (VEGF) expression in tumors: Induction of endothelial cell shedding and regression of hemangioblastoma-like vessels by VEGF withdrawal. Proc Natl Acad Sci U S A 1997;94(16):8761-6.

48. Gerber HP, Dixit V, Ferrara N. Vascular endothelial growth factor induces expression of the antiapoptotic proteins $\mathrm{Bcl}-2$ and $\mathrm{A} 1$ in vascular endothelial cells. J Biol Chem 19982;273(21):13313-6.

49. Olsson AK, Dimberg A, Kreuger J, Claesson-Welsh L. VEGF receptor signalling - In control of vascular function. Nat Rev Mol Cell Biol 2006;7(5):359-71

50. El-Arab LR, Swellam M, El Mahdy MM. Metronomic chemotherapy in metastatic breast cancer: Impact on VEGF. J Egypt Natl Canc Inst 2012;24(1):15-22.

51. Taha FM, Zeeneldin AA, Helal AM, Gaber AA, Sallam YA, Ramadan H, et al. Prognostic value of serum vascular endothelial growth factor in Egyptian females with metastatic triple negative breast cancer. Clin Biochem 2009;42(13-14):1420-6

52. Alsner J, Yilmaz M, Guldberg P, Hansen LL, Overgaard J. Heterogeneity in the clinical phenotype of TP53 mutations in breast cancer patients. Clin Cancer Res 2000;6(10):3923-31.

53. Tewari M, Krishnamurthy A, Shukla HS. Predictive markers of response to neoadjuvant chemotherapy in breast cancer. Surg Oncol 2008;17(4):301-11.

54. Sakuma K, Kurosumi M, Oba H, Kobayashi Y, Takei H, Inoue K, et al. Pathological tumor response to neoadjuvant chemotherapy using anthracycline and taxanes in patients with triple-negative breast cancer. Exp Ther Med 2011;2(2):257-64

55. Dookeran KA, Dignam JJ, Ferrer K, Sekosan M, McCaskill-Stevens W, Gehlert S. p53 as a marker of prognosis in African-American women with breast cancer. Ann Surg Oncol 2010;17(5):1398-405.

56. Yamashita H, Nishio M, Toyama T, Sugiura H, Zhang Z, Kobayashi S, et al. Coexistence of HER2 over-expression and p53 protein accumulation is a strong prognostic molecular marker in breast cancer. Breast Cancer Res 2004;6(1):R24-30.

57. Linjawi A, Kontogiannea M, Halwani F, Edwardes M, Meterissian S. Prognostic significance of $\mathrm{p} 53$, bcl-2, and Bax expression in early breast cancer. J Am Coll Surg 2004;198(1):83-90.

58. Miller LD, Smeds J, George J, Vega VB, Vergara L, Ploner A, et al. An expression signature for $\mathrm{p} 53$ status in human breast cancer predicts mutation status, transcriptional effects, and patient survival. Proc Natl Acad Sci U S A 2005;102(38):13550-5. 
59. Biganzoli E, Coradini D, Ambrogi F, Garibaldi JM, Lisboa P, Soria D, et al. p53 status identifies two subgroups of triple-negative breast cancers with distinct biological features. Jpn J Clin Oncol 2011;41(2):172-9.

60. Chae BJ, Bae JS, Lee A, Park WC, Seo YJ, Song BJ, et al. p53 as a specific prognostic factor in triple-negative breast cancer. Jpn J Clin Oncol 2009;39(4):217-24.

61. Maeda T, Nakanishi Y, Hirotani Y, Fuchinoue F, Enomoto K, Sakurai K, et al. Immunohistochemical co-expression status of cytokeratin $5 / 6$, androgen receptor, and p53 as prognostic factors of adjuvant chemotherapy for triple negative breast cancer. Med Mol Morphol 2016;49(1):11-21

62. Kim T, Han W, Kim MK, Lee JW, Kim J, Ahn SK, et al. Predictive significance of $\mathrm{p} 53, \mathrm{Ki}-67$, and $\mathrm{Bcl}-2$ expression for pathologic complete response after neoadjuvant chemotherapy for triple-negative breast cancer. J Breast Cancer 2015;18(1):16-21.

63. Dumay A, Feugeas JP, Wittmer E, Lehmann-Che J, Bertheau P, Espié M, et al. Distinct tumor protein p53 mutants in breast cancer subgroups. Int J Cancer 2013;132(5):1227-31. 